\title{
Ingestion efficiency of Macrobrachium rosenbergii (de Man) larvae feeding on Artemia, Moina micrura Kurz and their combination
}

\begin{abstract}
Ingestion efficiency of Macrobrachium rosenbergii (de Man) larvae feeding on Artemia alone (A), Moina alone (M) and a 50:50 mixture of Artemia and Moina (AM) at 1, 3, 5 and 7 organisms ml-1 densities was investigated in terms of individual ingestion rate (IIR), dry mass ingestion (DMI) and energy intake (EI). Irrespective of larval stages and test food densities, larvae showed a significantly higher IIR for diet A except for AM, as the IIR for A and AM were similar from stage $\mathrm{V}$ onwards. Compared with diet A, IIR of $\mathrm{M}$ were sevenfold to fourfold lower, up to stage V. However, the larvae showed a sharp increase in IIR thereafter and gradually the differences reduced to about 1.6-1.2 fold at later stages. Despite the lower IIR, both DMI and EI for Moina were higher from stage VIII onwards than values for Artemia. In case of mixed diet (AM), the larvae of all stages showed a food selectivity response.
\end{abstract}

Keyword: Individual ingestion rate (IIR); Dry mass ingestion (DMI); Energy intake (EI) 